[post-print version]

\title{
Attachment and mental help-seeking in the perinatal period: The role of stigma
}

\author{
Ana Fonseca, Mariana Moura-Ramos, \& Maria Cristina Canavarro
}

\begin{abstract}
This study aimed at 1) examining how women's attachment representations influence their intentions to seek formal help for their emotional problems, either directly or by affecting attitudes towards professional help-seeking (stigma and psychological openness), and 2) examining whether these effects were moderated by the presence of clinically significant psychopathological symptoms. A cross-sectional online survey including 226 women during the perinatal period was conducted.

Results showed that, when clinically significant psychopathological symptoms were present, women's more insecure attachment representations were associated with lower intentions to seek professional help, and this influence occurred throughout a decrease in women's indifference to stigma associated with mental healthcare. These results support both the intra and interpersonal nature of the help-seeking process, and highlight the importance of implementing stigma reduction strategies (e.g., awareness campaigns, health professional's non-judgmental questioning of emotional difficulties), particularly in women with clinically significant psychopathological symptoms.
\end{abstract}

Keywords: Attachment representations; Formal help-seeking intentions; Perinatal period; Psychological Openness; Stigma.

\section{Introduction}

Both depression (Gaynes et al., 2005) and anxiety (Henderson \& Redshaw, 2013) in the perinatal period (i.e., the period comprising the pregnancy and the first 12 months postpartum, Gaynes et al., 2005) are prevalent clinical conditions, with well-documented adverse effects on maternal health and well-being (Muzik \& Borovska, 2010) and on infant' development (Kingston, Tough, \& Whitfield, 2012; Tronick \& Reck, 2009). However, research shows that a minority of women (10-20\%) proactively seek formal/professional help for their mental health problems during the perinatal period, although treatment is available and effective (Dennis \& Chung-Lee, 2006; Fonseca, Gorayeb, \& Canavarro, 2015; O'Mahen \& Flynn, 2008). 
Help-seeking has been conceptualized as a social transaction between intrapersonal and interpersonal processes (Rickwood, Deane, Wilson, \& Ciarrochi, 2005). Help-seeking intrapersonal processes involve the individual's awareness and expression of personal needs, while help-seeking interpersonal processes comprise the individual's willingness to share and disclose their needs to others (Rickwood et al., 2005). Several factors may operate within those intra and interpersonal processes and influence women's formal help-seeking during the perinatal period. Two of such factors seem to be attachment representations and attitudes toward help-seeking.

Attachment (in)security is a powerful predictor of individual functioning (Alexander, Feeney, Hohaus, \& Noller, 2001) and, specifically, of help-seeking behaviors (Collins \& Feeney, 2000). Attachment (in)security has been operationalized according to two related dimensions: Attachmentrelated Anxiety and Attachment-related Avoidance (Griffin \& Bartholomew, 1994; Simpson, Rholes, Campbell, \& Wilson, 2003). Attachment Anxiety comprises representations of the self, namely the individuals' beliefs about one's own worth, and the degree to which they fear to be rejected by others (Griffin \& Bartholomew, 1994; Simpson et al., 2003). On the other hand, Attachment Avoidance comprises representations of the others, namely the individuals' beliefs about others' intentions and traits, and the degree to which one avoids intimacy and desires to maintain independence with others (Griffin \& Bartholomew, 1994; Simpson et al., 2003). While attachment security is characterized by positive representations of the self and of others (i.e., low scores for both Attachment Anxiety and Attachment Avoidance), attachment insecurity is characterized by high scores on Attachment Anxiety and/or Avoidance, reflecting more negative representations of the self and/or of others, respectively (Brennan, Clark, \& Shaver, 1998).

Attachment representations seem to influence how individuals evaluate the prospect of seeking professional help to address their mental health problems, their expectations concerning the type of support they may receive, and their decision to seek or to avoid professional help (Shaffer, Vogel, \& Wei, 2006; Vogel \& Wei, 2005). Secure attachment representations may be understood as an inner resource, not only in terms of adjustment to stress-inducing events (Mikulincer \& Florian, 1995, 1998), but also because individuals with secure attachment representations are more likely to acknowledge their distress (Nam \& Lee, 2015) and are more willing to seek formal help for their psychological distress (Moran, 2007; Zhao et al., 2015) than individuals with insecure attachment representations are. Different patterns of formal help-seeking have been found for individuals with insecure attachment representations. On the 
one hand, individuals with negative representations of others (i.e., high levels of Attachment Avoidance) tend to be more comfortable being more independent and self-reliant (Diener \& Monroe, 2011; Zhao et al., 2015), which translates into less willingness to acknowledge their distress and to seek professional help (Vogel \& Wei, 2005), and to a higher likelihood of rejecting treatment (Dozier, 1990), which is consistent with their desire to maintain distance from others and to avoid relying on them for help (Lopez \& Brennan, 2000). On the other hand, individuals with negative representations of the self (i.e., high levels of Attachment Anxiety) tend to overemphasize their distress in an attempt to elicit help from others (Lopez \& Brennan, 2000). Therefore, these anxiously-attached individuals are more likely to acknowledge their psychological distress and to seek professional help (Diener \& Monroe, 2011; Vogel \& Wei, 2005), although they may be indiscriminate in their help-seeking behaviors (Moran, 2007).

\section{Attachment representations and formal help-seeking for emotional problems during the} perinatal period: The role of help-seeking attitudes

Attitudes toward professional help-seeking have been consistently considered one of the primary determinants of formal help-seeking intentions (Barney, Griffiths, Jorm, \& Christensen, 2006; Have et al., 2000; Vogel \& Wester, 2003), in particular stigma and psychological openness. Stigma refers to the extent to which individuals are concerned about their significant others' opinion concerning their mental health problems and help-seeking behaviors (Ben-Porath, 2002; Mackenzie, Knox, Gekoski, \& Macaulay, 2004), while psychological openness refers to the extent to which individuals are concerned with the consequences of acknowledging and disclosing their distress to others (Mackenzie et al., 2004).

During the perinatal period, several studies have suggested that the stigma associated with postpartum depression may hinder women's recognition of the presence of perinatal distress symptoms and their help-seeking behaviors (Dennis \& Chung-Lee, 2006; O'Mahen \& Flynn, 2008), as they may feel shame and fear of being labeled as mentally ill and/or "bad mothers" (Abrams, Dornig, \& Curran, 2009; Dennis \& Chung-Lee, 2006; Bilszta, Ericksen, Buist, \& Milgrom, 2010; Callister, Beckstrand, \& Corbett, 2011). Research has also shown that women in the perinatal period may experience poor psychological openness toward sharing their emotional difficulties with health professionals, because they fear that their symptoms may not be understood by them, preferring to address the symptoms themselves and hoping for their spontaneous remission (Callister et al., 2011; Woolhouse, Brown, Krastev, Perlen, \& Gunn, 2009).

Research conducted in the general population suggests that individuals' attachment representations are associated with their attitudes toward professional help-seeking (Hill et al., 2012). 
Specifically, individuals with insecure attachment representations endorse higher levels of stigma for seeking formal help than individuals with secure attachment representations do (Nam \& Lee, 2015; Shaffer et al., 2006; Zhao et al., 2015). Furthermore, individuals with secure attachment representations seem to perceive health professionals as available and safe figures to whom they are willing to disclose their problems (Hill et al., 2012), suggesting higher levels of psychological openness. In contrast, individuals with insecure attachment representations show less psychological openness to share their emotional difficulties for different reasons. While individuals with negative representations of others perceive health professionals as cold and rejecting (Shaffer et al., 2006), individuals with negative representations of the self may show ambivalence between their willingness to self-disclose their problems (Dozier, 1990; Vogel \& Wei, 2005) and their fear of not being accepted by health professionals as a consequence of their self-disclosure (Shaffer et al., 2006).

\section{The current study}

The majority of existing research on this topic has been conducted within the general population. However, given the pervasive nature of untreated emotional difficulties during the perinatal period, it may be particularly important to better understand women's intentions to seek professional help to address their emotional problems during this period. Therefore, the first aim of this study was to examine the direct and indirect effects, via attitudes toward professional help-seeking (stigma and psychological openness), of women's attachment representations on their intentions to seek formal help for their emotional problems during the perinatal period. Existing research (e.g., Shaffer et al., 2006) allows us to hypothesize that individuals' attitudes towards professional help-seeking may be a mechanism by which the relationship between women's attachment representations and their help-seeking intentions may occur (see Figure 1).

\section{[Insert_Figure_1_about_here]}

Furthermore, the nature of the aforementioned relationships may be different as a function of women's actual need for help (i.e., if women present or do not present clinically significant psychopathological symptoms). There is evidence that psychological distress is positively associated with an individual's intentions to seek professional help (Cepeda-Benito \& Short, 1998; Vogel \& Wei, 2005), suggesting that the individual's recognition of an actual need for help may facilitate help seeking. However, there is also evidence that women present more negative attitudes towards professional helpseeking when they present clinically significant psychopathological symptoms (Manos, Rusch, Kanter, \& 
Clifford, 2009; Silva, 2015), suggesting that psychological distress may hinder the help-seeking process. Due to these inconsistencies, it is important to clarify whether current psychopathological symptoms may influence the mechanisms by which attachment representations affect the help-seeking process. Therefore, our second aim was to examine whether the strength of the direct and indirect effects was moderated by the presence of clinically significant psychopathological symptoms.

\section{Method}

\section{Procedure}

A cross-sectional study was conducted in Portugal, using an Internet survey that aimed to describe women's help-seeking intentions with regard to their mental health problems in the perinatal period. Data collection occurred between November 2014 and March 2015.

Eligibility criteria to participate in the study were the following: 1) being a woman; 2) being 18 years or older; and 3) being currently pregnant or having given birth during the previous 12 months. Participants were a self-selected (i.e., women who choose to participate in the survey) online sample who replied to advertisements posted on social media websites such as Facebook and on websites and forums focusing on pregnancy and childbirth. The advertisements contained information on the study goals and a weblink to the Internet survey (hosted by http://www.limesurvey.com/). After accessing the weblink, participants were given information about the roles of the participants' (e.g., the voluntary nature of their participation and the possibility of dropping out of the study at any time) and of the researchers (e.g., work to ensure confidentiality), and they provided their consent to participate in the study (by answering the question: "Do you agree to participate in this study?"). No incentives were given to participants. Finally, the participants were given the self-report questionnaires. The survey was hosted on a secure server, and the survey software prevented the same user from completing the survey more than once.

\section{Measures}

\section{Demographic and clinical information.}

The participants were asked demographic (age; marital status; educational level; professional status; place of residence; family household income) and clinical information (perinatal period pregnancy/postpartum period; number of prior children; history of psychiatric/psychological problems). 


\section{Experiences in Close Relationships - Relationship Structures Questionnaire (ECR-RS)}

(Fraley, Niedenthal, Marks, Brumbaugh, \& Vicary, 2006; Moreira, Martins, Gouveia, \&

Canavarro, 2015).

The ECR-RS examines attachment representations and is composed of nine items, rated on a seven-point Likert scale ranging from 1 (Strongly Disagree) to 7 (Strongly Agree). Participants were instructed to respond to the questions by considering their close relationships in general. The ECR-RS is comprised of two subscales: Attachment-related Anxiety (3 items) and Attachment-related Avoidance (6 items). Higher scores indicate higher Attachment-related Avoidance and Attachment-related Anxiety. In this study, the Cronbach's alphas were .84 (Attachment-related Avoidance) and .90 (Attachment-related Anxiety).

\section{Inventory of Attitudes Towards Seeking Mental Health Services (IATSMHS) (Fonseca,} Silva, \& Canavarro, 2015; Mackenzie et al., 2004).

The IATSMHS is composed of 24 items rated on a 5-point Likert scale, ranging from 0 (Disagree) to 4 (Agree). The IATSMHS includes three factors, each consisting of eight items: Psychological Openness, Help-seeking Propensity, and Indifference to Stigma. Higher scores indicate the presence of more positive attitudes toward seeking professional help. In the present study, we used only the dimensions Psychological Openness and Indifference to Stigma, with Cronbach's alphas of .63 and .83 , respectively.

\section{General Help-seeking Questionnaire (GHSQ) (Rickwood et al., 2005).}

In the GHSQ, the participants were asked to answer regarding their intentions to ask for help from different sources to address personal/emotional issues on a 7-point Likert scale ranging from 1 (extremely unlikely) to 7 (extremely likely). It is possible to calculate the intention to ask for help from different types of sources, including: formal help (e.g., mental health professionals, family doctors/general practitioners), semi-formal help (e.g., priest, telephone help-line), informal help (e.g., partner, friend, father/mother, other relative) and self-help (e.g., the internet) (Rickwood \& Thomas, 2012). Higher scores indicate higher intentions to seek help from these sources. In the present study, only the formal help dimension was used.

Edinburgh Postnatal Depression Scale (EPDS) (Areias, Kumar, Barros, \& Figueiredo, 1996; Augusto, Kumar, Calheiros, Matos, \& Figueiredo, 1996; Cox, Holden, \& Sagovsky, 1987). 
The EPDS is a 10-item screening scale for antepartum and postpartum depression. Women were asked to rate their emotions (e.g., sadness, tearfulness) over the previous seven days, using a 4-point Likert scale. In the Portuguese validation studies, a score of 9 or higher indicates a possible depressive disorder (Areias et al., 1996; Augusto et al., 1996). In our sample, Cronbach's alpha was .91.

\section{Hospital Anxiety and Depression Scale (HADS) (Pais-Ribeiro et al., 2007).}

The HADS is a self-report scale comprised of 14 items with a 4-point response scale that assess the levels of anxiety and depression felt over the previous seven days. The HADS includes two subscales: the Anxiety subscale and the Depression subscale, each one with seven items. Higher scores indicate higher levels of Anxiety and/or Depression. A score higher than 8 is considered by the authors as worthy of clinical attention. In this study, only the Anxiety subscale was used (Cronbach's alpha: .87).

Based on their scores on the EPDS and HADS, women were classified as presenting clinically significant psychopathological symptoms (women who scored on EPDS > 9 and/or Anxiety HADS > 8; Areias et al., 1996; Augusto et al., 1996; Pais-Ribeiro et al., 2007) and women who did not present clinically significant psychopathological symptoms.

\section{Participants}

A total of 226 women completed the entire protocol survey. The women's mean age was 30.08 years ( $S D$ =4.12). Most women were married/cohabiting $(n=189,83.6 \%)$, were currently employed $(n=167$, $73.9 \%)$, had a household income of $1000 €-2000 €(n=103,45.6 \%)$, and lived in an urban area $(n=178$, $78.8 \%)$. For the majority of women this is their first child $(n=154,68.1 \%)$, and they had given birth in the last 12 months ( $n=160,70.8 \%, M=5.70$ months, $S D=3.72$ months), whereas $29.2 \%$ of the women were currently pregnant $(M=24.45$ weeks pregnant, $S D=11.14$ weeks $)$. Concerning psychiatric history, $35.4 \%$ of the women $(n=80)$ had a history of psychiatric/psychological problems. Moreover, $38.9 \%$ of the women $(n=88)$ presented clinically significant psychopathological problems.

\section{Results}

\section{Preliminary analysis}

Descriptive statistics and bivariate correlations were calculated to examine the pattern of direct relationships between the variables, and are reported in Table 1. 
All variables were compared across the two groups of women (women who did not present [Group 1] or who did present [Group 2] clinically significant psychopathological problems), using univariate and multivariate analyses. Differences were found regarding attachment representations (Wilk's Lambda $\left.=.81, F_{(2,223)}=26.30, p<.001, \eta^{2}{ }_{p}=.19\right)$. Women without clinically significant psychopathological symptoms reported lower Attachment Anxiety $(M=2.95 v s . M=4.52)$ and lower Attachment Avoidance $(M=2.77$ vs. $M=3.44)$ than women with clinically significant psychopathological symptoms $\left(F_{(1,224)}=42.17, p<.001, \eta_{\mathrm{p}}^{2}=.16\right.$ and $F_{(1,224)}=18.19, p<.001, \eta_{\mathrm{p}}^{2}=$ .08 , respectively).

Differences across groups were also found in the attitudes towards professional help-seeking (Wilk's Lambda $\left.=0.9, F_{(2,223)}=11.11, p<.001, \eta_{\mathrm{p}}^{2}=.19\right)$. Women without clinically significant psychopathological symptoms reported higher Psychological Openness $(M=2.79 v s . M=2.47)$ and higher Indifference to Stigma $(M=3.45 v s . M=3.03)$ than women with clinically significant psychopathological symptoms $\left(F_{(1,224)}=12.13, p \leq .001, \eta_{\mathrm{p}}^{2}=.05\right.$ and $F_{(1,224)}=17.30, p<.001, \eta_{\mathrm{p}}^{2}=$ .07 , respectively).

No differences were found across groups regarding the Intention to Use Formal Help-Seeking $\left[F_{(1,224)}=2.168, p=.142, \eta_{\mathrm{p}}^{2}=.01\right]$.

\section{Examining the indirect effects of attachment representations on intentions to use formal help- seeking}

A path analysis model examining the indirect effects of attachment representations (Anxiety and Avoidance) on Intentions to use Formal Help-Seeking by affecting attitudes toward professional helpseeking (Psychological Openness and Indifference to Stigma) was tested (see Figure 2), using the maximum likelihood estimation method (with AMOS). According to Kline (2005), the sample size required to perform a path analysis should take into consideration the complexity of the model, namely, the ratio between the number of participants and the parameters to be estimated, which should be approximately 10 . In this study, the ratio between sample size and free parameter estimates was 16.14 , indicating that the sample size was adequate to conduct a path analysis. To allow for model identification, the parameter of the correlation between the attachment orientations was fixed at 1 . The overall model fit was ascertained using the chi-square goodness-of-fit statistic, the comparative fit index (CFI) and the 
standardized root-mean-square residual (SRMR), following the recommendation of Hu \& Bentler (1998) of using a two-index presentation strategy.

\section{[Insert Figure 2 about here]}

The results indicated that the model had a very good fit to the data $\left(\chi^{2}=5.72, d f=1, p=.02 ; \mathrm{CFI}\right.$ $=0.97$; SRMR = 0.05), as the CFI was greater than 0.95, and the SRMR was below .08 (Hu \& Bentler, 1998). There were no significant direct effects of attachment representations on intentions to use formal help seeking.

Bootstrap procedures were used to test for the significance of the indirect effects, in accordance with recent recommendations (MacKinnon \& Fairchild, 2009; Shrout \& Bolger, 2002), by estimating the 95\% bias corrected confidence interval (BCCI). Indirect effects are considered significant if the bootstrapped confidence interval does not include 0 . The bootstrap confidence intervals (2000 bootstrap samples) of the indirect effects indicated significant effects on the relationship between attachment representations and Intentions to use Formal Help-Seeking (95\% BCCI -0.17, -0.03 and 95\% BCCI -0.11, -0.05, for Anxiety and Avoidance, respectively) (Figure 2), and this effect occurred through affecting Stigma, and not Psychological Openness.

The empirical power tables proposed by Fritz and MacKinnon (2007) for mediation models suggest that the sample size of this study is sufficient to find a mediated effect that includes small to medium effects in a and $\mathrm{b}$ paths with a power of .80 .

\section{Multigroup comparison of the indirect effect model}

The path model described above was tested in a multigroup design that allowed for the comparison the indirect effects on Group 1 (women without clinically significant psychopathological symptoms) and Group 2 (women with clinically significant psychopathological symptoms). In this model, we first tested the configural model, in which the same factor structure (that is, no equality constrains are imposed on any of the parameters) was tested simultaneously for both groups. Secondly, we examined the equality of structural weights of the variables in the model. Significant chi-square changes $\left(\Delta \chi^{2}\right)$ indicate that the path model is different across groups.

In the multigroup comparison, the unconstrained model, where the model with free estimates is tested separately for both groups, was compared to a subsequent model, where equally constraints are imposed. The change in the model fit was significant $\left[\Delta \chi^{2}(8)=20.22, p=.010\right]$, indicating a deterioration 
in model fit. That is, when the paths of the model were constrained to equality in both groups, the model revealed a poorer fit, suggesting that model relationships were different across groups. Indeed, the indirect effects of the relationship between attachment representations and Intentions to use Formal HelpSeeking were non-significant for Group 1 (95\% BCCI -0.16, 0.01 and BCCI -0.08, 0.01, for Anxiety and Avoidance, respectively), but were significant for Group 2 (95\% BCCI -0.28, -0.02 and BCCI -0.31, 0.01, for Anxiety and Avoidance, respectively). The model for each group is depicted in Figure 3.

[Insert Figure 3 about here]

\section{Discussion}

The present study adds to existing knowledge on the factors that influence women's formal helpseeking to address their mental health problems during the perinatal period, with two main findings: a) women's more insecure attachment representations (anxiety and avoidance) were associated with lower intentions to seek professional help, and this influence occurred through a decrease in women's indifference to stigma associated with mental healthcare; and b) this influence only occurred when women presented clinically significant psychopathological symptoms, that is, an actual need for help.

Contrary to prior existing research (Moran, 2007; Zhao et al., 2015), the results of this study highlight that women's attachment representations do not directly influence their intentions to seek professional help to address their emotional difficulties during the perinatal period, supporting the proposed indirect nature of these effects, as discussed below. However, preliminary results showed a significant and negative association between women's negative representations of others (attachmentrelated avoidance) and formal help-seeking intentions, but no relationship was found between negative representations of the self (attachment-related anxiety) and formal help-seeking intentions. These results suggest that women with negative representations of others may be less willing to seek professional help (Vogel \& Wei, 2005; Zhao et al., 2015), as they learned to see others as unavailable and/or inconsistently responsive in the context of their caregiving interactions (Collins \& Feeney, 2000; Simpson, Rholes, \& Nelligan, 1992), which may preclude them to show vulnerability when they think that health professionals would not provide an effective help. On the other hand, women with negative representations of the self do not present a clearer pattern of help-seeking intentions because they may be simultaneously likely and reluctant to seek professional help (Shaffer et al., 2006; Vogel \& Wei, 2005).

In fact, the effect of women's attachment representations on their formal help-seeking intentions seems to occur indirectly by affecting indifference to stigma. These results allow us to reflect on several 
points. First, more insecure attachment representations were associated with more negative attitudes toward seeking professional help, in accordance with prior research (Nam \& Lee, 2015; Shaffer et al., 2006). On the one hand, women's negative representations of others as unavailable and unsupportive (Mikulincer \& Shaver, 2005) may lead them not only to be less open to disclosing their emotional problems to health professionals (Vogel \& Wei, 2005), but also to be more susceptible to stigma because they may believe that health professionals would be unsupportive (Shaffer et al., 2006) and judgmental, which may lead to more negative attitudes toward professional help-seeking. Moreover, these results are consistent with the evidence that women with negative representations of others tend to engage in few support-seeking strategies to address stressful situations during the transition to parenthood (Rholes, Simpson, Campbell, \& Grich, 2001; Simpson, Rholes, Campbell, Tran, \& Wilson, 2003) because turning to others for support will compromise their emotional self-sufficiency and their desire to limit intimacy (Alexander et al., 2001).

On the other hand, women's negative representations of the self as having low self-worth (Mikulincer \& Shaver, 2005) tend to overemphasize their fear of rejection/abandonment, resulting in ambivalence between continuous support seeking and the perception that the support they receive is insufficient (Alexander et al., 2001; Simpson, Rholes, Campbell, Tran, et al., 2003). These women's tendency to negatively evaluate the availability of support from others and the fear of not being accepted by health professionals as a consequence of sharing their difficulties (Shaffer et al., 2006), may make them prone to more negative attitudes toward professional help-seeking.

Second, our results highlight the important role of attitudes toward seeking professional help in understanding women's help-seeking process. As suggested by other studies (e.g., Dennis \& Chung-Lee, 2006; O'Mahen \& Flynn, 2008), attitudinal barriers, particularly stigma, are important barriers in women's help-seeking process because women report that they feel ashamed that their perinatal distress symptoms may be interpreted as signs of personal failure and fear disapproval from their social network (Abrams et al., 2009; Bilszta et al., 2010). In fact, there is some evidence that individuals' perceived stigma concerning psychological problems may preclude them to share their difficulties with their social network when facing stress-inducing events, which may intensify their psychopathological symptoms (Britt et al., 2008). Globally, women's more insecure attachment representations may lead to an increased preoccupation with their social network's opinions about their emotional distress and professional helpseeking, either because they want to be perceived as invulnerable and self-sufficient (even when help is 
needed) or because they fear rejection from others, which may lead to lower indifference to stigma and, consequently, may hinder women's intentions to seek professional help. The fact that only stigma, but not psychological openness, emerged as a significant explanatory mechanism for the relationship between women's attachment representations and formal help-seeking intentions was also congruent with a prior study that found that stigma was the most important barrier to women's help-seeking process (Silva, 2015).

Furthermore, although attachment representations seem to influence women's attitudes toward professional help-seeking, regardless of the presence of clinically significant psychopathological symptoms, the indirect effect of attachment representations on formal help-seeking intentions through indifference to stigma only occurs when women present clinically significant psychopathological symptoms, that is, an actual need for help. It is possible that the presence of an actual need for help predisposes these women to a more careful consideration of the benefits, as well as the risks of seeking formal help, such as being stigmatized (Abrams et al., 2009; Dennis \& Chung-Lee, 2006). Moreover, because psychopathological symptoms are usually associated with a more negative view of events, it is possible that, as suggested by our preliminary results and by prior research, the presence of psychopathological symptoms will result in an increased salience of stigmatizing attitudes toward depression and in a more negative view of the consequences that may result from disclosing one's depressed status (Manos et al., 2009) and seeking professional help, which may hinder women's formal help-seeking intentions. These hypotheses should be explored further.

Despite the research contributions of this study, our results should be interpreted with caution due to some limitations that should be acknowledged. First, the study's cross-sectional design prevents the establishment of causal relationships among the variables, although the directional paths tested in the analyses were grounded in theoretical models (Attachment Theory, Bowlby, 1969) and previous empirical research. Second, given the self-selected nature of the participants' responses to the online survey, people who were willing to participate in this study may be more interested in the topic of helpseeking. Moreover, our sample consisted mainly of married women with high educational levels and high income, and no information was collected concerning ethnical background. For these reasons, and despite being similar to other female samples in the perinatal period, our sample may not be entirely representative of the population, compromising the generalizability of findings, and future studies should use a more diverse sample in terms of sociodemographic characteristics. Third, data collection was based 
exclusively on self-report questionnaires; although self-report measures allow the identification of women presenting psychopathological symptoms that may be worthy of clinical attention, this does not ensure a clinically diagnosis of anxiety/depression. Fourth, the reliability values of the Psychological Openness dimension in our sample were below the threshold of .70, which may also compromise the interpretation of our findings. Finally, although the sample size warranted the power to perform the path analysis and to detect indirect effects, the sample of the subgroups for the multigroup analysis was small, which may have affected the power to detect small effects. Further analyses with larger samples are recommended. In conclusion, our results seem to support the intra-interpersonal nature of the help-seeking process (Rickwood et al., 2005). Initially, the help-seeking process has mainly an intrapersonal nature because it depends not only on women's recognition of an actual need for help (i.e., the presence of clinically significant psychopathological symptoms) but also on the important influence of their individual characteristics such as attachment representations, which influence how women interpret and cope with stress-inducing situations. However, as suggested by the women's susceptibility to stigma (i.e., the relevance of perceived opinions of the women's social networks about their emotional distress and professional help-seeking), the help-seeking process gradually assumes an interpersonal nature to women. The findings of the present study are clinically relevant for several reasons. First, our results emphasize that interventions to promote professional help-seeking should be directed to women who present an actual need for help (i.e., clinically significant psychopathological symptoms), justifying the need to systematically screen women for psychopathological symptoms at different times during the perinatal period. Second, given the important role of stigma in explaining help-seeking intentions, awareness campaigns that target women with an actual need for help are required. These campaigns should focus on myths about motherhood, the prevalence of perinatal mood disorders, treatment options and the risks of not seeking treatment (Bilszta et al., 2010). Moreover, health professionals should be trained to adopt a non-stigmatizing attitude toward these women, by openly asking about women's emotional difficulties during the perinatal period (e.g., emotional changes), showing availability and empathetically listening to women's concerns with a non-judgmental attitude, and providing personalized information to women about their symptoms and treatment options (Goodman, 2009). Finally, health professionals should be aware that insecure attachment representations may make women prone to more negative attitudes toward professional help-seeking by influencing women's appraisal of help-seeking (i.e., seeing help-seeking as threatening because of their fear of intimacy or rejection). In order to mitigate this effect, it is important to 
promote a more thoughtful appraisal of the help-seeking process by these women, by actively triggering open and nonjudgmental discussions about this topic, where they can provide accurate information and clarify women's misconceptions about the benefits and risks of help-seeking.

\section{Compliance with Ethical Standards}

Ethical standards and procedures for research with human beings (e.g., Helsinki Declaration, World Medical Association, 2001; American Psychological Association, 2010) were followed, and this study was approved by the Institutional Review Board of the Faculty of Psychology and Educational Sciences of the University of Blind for Review. Informed consent was obtained from all participants included in the study.

All authors certify that they accept responsibility for the conduct of the study and for the analysis and interpretation of the data; that they helped write the manuscript and agree with the decisions about it; that they meet the definition of an author as stated by the International Committee of Medical Journal Editors; and that they have seen and approved the final manuscript.

Conflict of interest: None.

\section{References}

Abrams, L. S., Dornig, K., \& Curran, L. (2009). Barriers to service use for postpartum depression symptoms among low-income ethnic minority mothers in the United States. Qualitative Health Research, 19, 535-551. doi:10.1177/1049732309332794

Alexander, R., Feeney, J., Hohaus, L., \& Noller, P. (2001). Attachment style and coping resources as predictors of coping strategies in the transition to parenthood. Personal Relationships, 8, 137152. doi:10.1111/j.1475-6811.2001.tb00032.x

Areias, M., Kumar, R., Barros, H., \& Figueiredo, E. (1996). Comparative incidence of depression in women and men, during pregnancy and after childbirth: Validation of the Edinburgh Postnatal Depression Scale in Portuguese Mothers. British Journal of Psychiatry, 169, 30-35. doi:10.1192/bjp.169.1.30

American Psychological Association (2010). Publication Manual of the American Psychological Association. London: American Psychological Association. 
Augusto, A., Kumar, R., Calheiros, J., Matos, E., \& Figueiredo, E. (1996). Post-natal depression in an urban area of Portugal: Comparison of childbearing women and matched controls. Psychological Medicine, 26, 135-141. doi:10.1017/S0033291700033778

Barney, L., Griffiths, K. M., Jorm, A. F., \& Christensen, H. (2006). Stigma about depression and its impact on help-seeking intentions. Australian and New Zealand Journal of Psychiatry, 40, 5154. doi:10.1080/j.1440-1614.2006.01741.x

Ben-Porath, D. (2002). Stigmatization of individuals who receive psychotherapy: An interaction between help-seeking behavior and the presence of depression. Journal of Social and Clinical Psychology, 21, 400-413. doi:10.1521/jscp.21.4.400.22594

Bilszta, J., Ericksen, J., Buist, A., \& Milgrom, J. (2010). Women's experience of postnatal depression: Beliefs and attitudes as barriers to care. Australian Journal of Advanced Nursing, 27, 44-54.

Bowlby, J. (1969). Attachment and Loss: Vol. 1. Attachment. New York: Basic Books.

Brennan, K., Clark, C. L., \& Shaver, P. R. (1998). Self-report measurement of adult romantic attachment: An integrative overview. In J. A. Simpson \& W. S. Rholes (Eds.), Attachment theory and close relationships (pp. 46-76). New York: Guilford Press.

Britt, T., Greene-Shortridge, T., Brink, S., Nguyen, Q., Rath, J., Cox, A., . . Castro, C. (2008). Perceived stigma and barriers to care for psychological treatment: Implications for reactions to stressors in different contexts. Journal of Social and Clinical Psychology, 27, 317.335. doi:10.1521/jscp.2008.27.4.317

Callister, L. C., Beckstrand, R. L., \& Corbett, C. (2011). Postpartum depression and help-seeking behaviors in immigrant Hispanic women. Journal of Obstetrics Gynecological and Neonatal Nursing, 40, 440-449. doi:10.1111/j.1552-6909.2011.01254.x

Cepeda-Benito, A., \& Short, P. (1998). Self-concealment, avoidance of psychological services, and perceived likelihood of seeking professional help. Journal of Counseling Psychology, 45, 58-64. doi:10.1037/0022-0167.45.1.58

Collins, N., \& Feeney, B. (2000). A safe haven: An attachment theory perspective on support seeking and caregiving in intimate relationships. Journal of Personal and Social Psychology, 78, 1053-1073. doi:10.1O37//OO22-3514.78.6.1053 
Cox, J., Holden, J. M., \& Sagovsky, R. (1987). Detection of postnatal depression: Development of the 10item Edinburgh Postnatal Depression Scale. British Journal of Psychiatry, 150, 782-786. doi:10.1192/bjp.150.6.782

Dennis, C. L., \& Chung-Lee, L. (2006). Postpartum Depression help-seeking barriers and maternal treatment preferences: A qualitative systematic review. Birth, 33, 323-331. doi:10.1111/j.1523536X.2006.00130.x

Diener, M., \& Monroe, J. (2011). The relationship between adult attachment style and therapeutic alliance in individual psychotherapy: A meta-analytic review. Psychotherapy, 48, 237-248. doi:10.1037/a0022425

Dozier, M. (1990). Attachment organization and treatment use for adults with serious psychopathological disorders. Development and Psychopathology, 2, 47-60. doi:10.1017/S0954579400000584

Fonseca, A., Gorayeb, R., \& Canavarro, M. C. (2015). Women's help-seeking behaviours for depressive symptoms during the perinatal period: Socio-demographic and clinical correlates and perceived barriers to seeking professional help. Midwifery, 31, 1177-1185. doi:10.1016/j.midw.2015.09.002

Fonseca, A., Silva, S., \& Canavarro, M. C. (2015). Inventário de Attitudes face à Procura de Serviços de Saúde Mental: Estudo das Características Psicométricas [Inventory of Attitudes Towards Seeking Mental Health Services: Psychometric properties]. Submitted manuscript.

Fraley, R. C., Niedenthal, P. M., Marks, M. J., Brumbaugh, C. C., \& Vicary, A. (2006). Adult attachment and the perception of emotional expressions: Probing the hyperactivating strategies underlying anxious attachment. Journal of Personality, 74, 1163-1190. doi:10.1111/j.14676494.2006.00406.x

Fritz, M. S., \& MacKinnon, D. P. (2007). Required sample size to detect the mediated effect. Psychological Science, 18, 233-239. doi:10.1111/j.1467-9280.2007.01882.x

Gaynes, B., Gavin, N., Meltzer-Brody, S., Lohr, K., Swinson, T., Gartlehner, G., . . Miller, W. (2005). Perinatal depression: Prevalence, screening accuracy and screening outcomes. Evidence Report/Technology Assessment (Vol. 119). RockVille, MD: Agency for Healthcare Research and Quality.

Goodman, J. H. (2009). Women's attitudes, preferences and perceived barriers to treatment for perinatal depression. Birth, 36, 60-69. doi:10.1111/j.1523-536X.2008.00296.x 
Griffin, D., \& Bartholomew, K. (1994). Models of the self and other: Fundamental dimensions underlying measures of adult attachment Journal of Personality and Social Psychology, 67, 430-445. doi:10.1037/0022-3514.67.3.430

Have, M., de Graaf, R., Ormel, J., Vilagut, G., Kovess, V., Alonso, J., \& Investigators, t. E. M. (2000). Are attitudes towards mental help-seeking associated with service use? Results from the European Study of Epidemiology of Mental Disorders. Social Psychiatry and Epidemiology, 45, 153-163. doi:10.1007/s00127-009-0050-4

Henderson, J., \& Redshaw, M. (2013). Anxiety in the perinatal period: Antenatal and postnatal influences and women's experience of care. Journal of Reproductive and Infant Psychology, 31, 465-478. doi:10.1080/02646838.2013.835037

Hill, C., Satterwhite, D., Larrimore, M., Mann, A., Johnson, C., Simon, R., . . Knox, S. (2012). Attitudes about psychotherapy: A qualitative study of introductory psychology students who have never been in psychotherapy and the influence of attachment style. Counselling and Psychotherapy Research, 12, 13-24. doi:10.1080/14733145.2011.629732

Hu, L., \& Bentler, P. M. (1998). Fit indices in covariance structure modeling: Sensitivity to underparameterized model misspecification. Pscyhological Methods, 3, 424-453. doi:10.1037/1082-989X.3.4.424

Kingston, D., Tough, S., \& Whitfield, H. (2012). Prenatal and postpartum maternal psychological distress and infant development: a systematic review. Child Psychiatry and Human Development, 43, 683-714. doi:10.1007/s10578-012-0291-4

Kline, R. (2005). Principles and practice of structural equation modeling (2nd ed.). New York: Guilford Press.

Lopez, F., \& Brennan, K. A. (2000). Dynamic processes underlying adult attachment organization: Toward an attachment theoretical perspective on the healthy and effective self. Journal of Counseling Psychology, 47, 283-300. doi:10.1037/0022-0167.47.3.283

Mackenzie, C., Knox, V., Gekoski, W., \& Macaulay, H. (2004). An adaptation and extension of the Attitudes Toward Seeking Professional Psychological Help Scale. Journal of Applied Social Psychology, 34, 2410-2435. doi:10.1111/j.1559-1816.2004.tb01984.x

MacKinnon, D. P., \& Fairchild, A. J. (2009). Current directions in mediation analysis. Current Directions in Psychological Science, 18, 16-20. doi:10.1111/j.1467-8721.2009.01598.x 
Manos, R. C., Rusch, L., Kanter, J. W., \& Clifford, L. (2009). Depression self-stigma as a mediator of the relationship between depression severity and avoidance. Journal of Social and Clinical Psychology, 28, 1128-1143. doi:10.1521/jscp.2009.28.9.1128

Mikulincer, M., \& Florian, V. (1995). Appraisal and coping with a real-life stressful situation: The contribution of attachment styles. Personality and Social Psychology Bulletin, 69, 1203-1215. doi:10.1177/0146167295214011

Mikulincer, M., \& Florian, V. (1998). The relationship between adult attachment styles and emotional and cognitive reactions to stressful events. In J. A. Simpson \& W. S. Rholes (Eds.), Attachment theory and close relationships (pp. 143-165). New York: Guilford.

Mikulincer, M., \& Shaver, P. R. (2005). Mental representations of attachment security: Theoretical foundation for a positive social psychology. In M. W. Baldwin (Ed.), Interpersonal Cognition (pp. 233-266). New York: The Guilford Press.

Moran, P. (2007). Attachment style, ethnicity and help-seeking attitudes among adolescent pupils. British Journal of Guidance \& Counselling, 35, 205-218. doi:10.1080/03069880701256627

Moreira, H., Martins, T., Gouveia, M. J., \& Canavarro, M. C. (2015). Assessing adult attachment across different contexts: Validation of the Portuguese version of the Experiences in Close Relationships - Relationship Structures questionnaire. Journal of Personality Assessment, 97, 2230. doi:10.1080/00223891.2014.950377

Muzik, M., \& Borovska, S. (2010). Perinatal depression: Implications for child mental health. Mental Health in Family Medicine, 7, 239-247.

Nam, S., \& Lee, S. (2015). The role of attachment and stigma in the relationship between stress and attitudes toward counseling in South Korea. Journal of Counseling \& Development, 93, 212-224. doi:10.1002/j.1556-6676.2015.00197.x

O'Mahen, H. A., \& Flynn, H. A. (2008). Preferences and perceived barriers to treatment for depression during the perinatal period. Journal of Women's Health, 17, 1301-1309. doi:10.1089/jwh.2007.0631

Pais-Ribeiro, J., silva, I., Ferreira, T., Martins, A., Meneses, R., \& Baltar, M. (2007). Validation study of a Portuguese version of The Hospital Anxiety and Depression Scale. Psychology, Health \& Medicine, 12, 225-237 doi:10.1080/13548500500524088 
Rholes, W. S., Simpson, A., Campbell, L., \& Grich, J. (2001). Adult attachment and the transition to parenthood. Journal of Personality and Social Psychology, 81, 421-435. doi:10.1037//O0223514.81.3.421

Rickwood, D., Deane, F., Wilson, C. J., \& Ciarrochi, J. (2005). Young people's help-seeking for mental health problems. Australian e-Journal for the Advancement of Mental Health, 4, 1-34.

Rickwood, D., \& Thomas, K. (2012). Conceptual measurement framework for help-seeking for mental health problems. Psychology Research and Behavior Management, 5, 173-183. doi:10.2147/PRBM.S38707

Shaffer, P., Vogel, D. L., \& Wei, M. (2006). The mediating roles of anticipated risks, anticipated benefits, and attitudes on the decision to seek professional help: An attachment perspective. Journal of Counseling Psychology, 53, 442-452. doi:10.1037/0022-0167.53.4.442

Shrout, P. E., \& Bolger, N. (2002). Mediation in experimental and nonexperimental studies: New procedures and recommendations. Psychological Methods, 7, 422-445. doi:10.1037//1082989X.7.4.422

Silva, S. (2015). Intenções e comportamentos efetivos de procura de ajuda das mulheres para lidar com dificuldades emocionais: Barreiras e facilitadores no período perinatal [Women's help-seeking intentions and behaviors for mental health problems during the perinatal period: Barriers and facilitators]. Unpublished Master Dissertation, University of Coimbra.

Simpson, J. A., Rholes, W. S., Campbell, L., Tran, S., \& Wilson, C. (2003). Adult attachment, the transition to parenthood, and depressive symptoms. Journal of Personality and Social Psychology, 84, 1172-1187. doi:10.1037/0022-3514.84.6.1172

Simpson, J. A., Rholes, W. S., Campbell, L., \& Wilson, C. (2003). Changes in attachment orientations across the transition to parenthood. Journal of Experimental Social Psychology, 39, 317-331. doi:10.1016/S0022-1031(03)00030-1

Simpson, J. A., Rholes, W. S., \& Nelligan, J. (1992). Support seeking and support giving within couples in an anxiety-provoking situation: The role of attachment styles. Journal of Personality and Social Psychology, 62, 434-446. doi:10.1037/0022-3514.62.3.434

Tronick, E., \& Reck, C. (2009). Infants of depressed mothers. Harvard Review of Psychiatry, 17, 147156. doi:10.1080/10673220902899714 
Vogel, D. L., \& Wei, M. (2005). Adult attachment and help-seeking intent: The mediating roles of perceived social support and psychological distress. Journal of Counseling Psychology, 52, 347357. doi:10.1016/j.jpsychores.2007.11.011

Vogel, D. L., \& Wester, S. R. (2003). To seek help or not to seek help: The risks of self-disclosure. Journal of Counseling Psychology, 50, 351-361. doi:10.1037/0022-0167.50.3.351

Woolhouse, H., Brown, S., Krastev, A., Perlen, S., \& Gunn, J. (2009). Seeking help for anxiety and depression after childbirth: Results of the Maternal Health Study. Archives of Women's Mental Health, 12, 75-83. doi:10.1007/s00737-009-0049-6

World Medical Association (2001). Worl Medical Association Declaration of Helsinki: Ethical principles for medical research involving human subjects. Bulletin of the World Health Organization, 79, 373-374.

Zhao, W., Young, R., Breslow, L., Michel, N. M., Flett, G. L., \& Goldberg, J. O. (2015). Attachment style, relationship factors, and mental health stigma among adolescents. Canadian Journal of Behavioural Science. doi:10.1037/cbs0000018 
Table 1.

Descriptives and Pearson's correlations between women's attachment representations, attitudes towards professional help-seeking and formal help-seeking intentions $(N=226)$

\begin{tabular}{|c|c|c|c|c|c|c|}
\hline & Mean & $S D$ & $\begin{array}{c}\text { Attachment } \\
\text { Anxiety }\end{array}$ & $\begin{array}{l}\text { Attachment } \\
\text { Avoidance }\end{array}$ & $\begin{array}{c}\text { Psychological } \\
\text { Openness }\end{array}$ & $\begin{array}{c}\text { Indifference } \\
\text { to Stigma }\end{array}$ \\
\hline Attachment Anxiety & 3.56 & 1.92 & - & & & \\
\hline Attachment Avoidance & 3.03 & 1.21 & 0.25 & - & & \\
\hline Psychological Openness & 2.67 & 0.69 & $-0.32^{* * *}$ & $-0.29^{* * *}$ & - & \\
\hline Indifference to Stigma & 3.29 & 0.75 & $-0.48^{* * *}$ & $-0.35^{* * *}$ & $0.40^{* * *}$ & - \\
\hline Formal Help-seeking Intentions & 4.48 & 1.59 & -0.04 & $-0.14^{*}$ & 0.13 & $0.19^{* *}$ \\
\hline
\end{tabular}

Note. ${ }^{*} p<0.05 ;{ }^{* *} p<0.01 ;{ }^{* * *} p<0.001$ 


\section{Figure Captions}

Figure 1. The direct and indirect effects of the relationship between attachment representations and formal help-seeking intentions through attitudes toward professional help-seeking.

Figure 2. Direct and indirect effects of the attachment representations on intentions to use formal help-seeking.

Note: Values are standardized coefficients. ${ }^{*} p<0.05 ; * * p<0.001$.

Figure 3. Direct and indirect effects of the attachment representations on intentions to use formal help-seeking in the two groups of participants.

Note: Values are standardized coefficients. ${ }^{*} p<0.001$. 


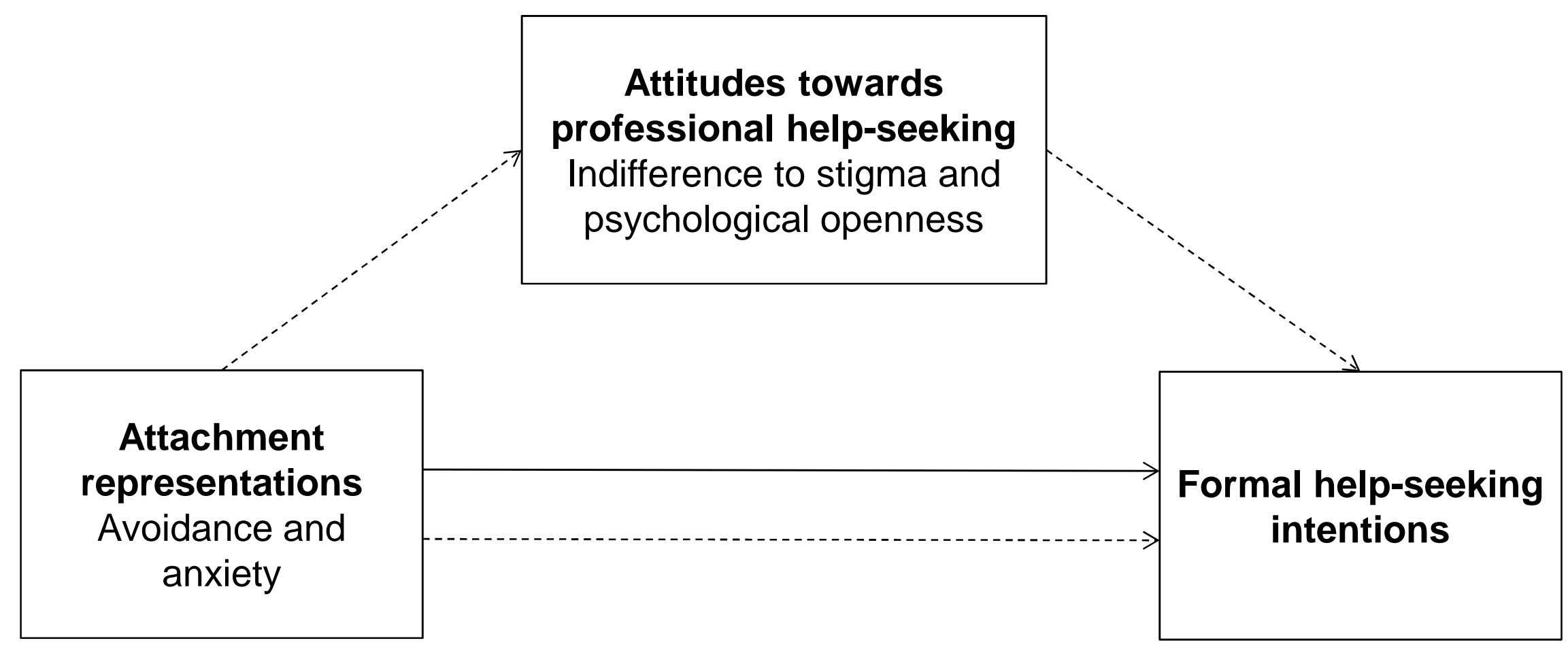

Figure 1. The direct and indirect effects of the relationship between attachment representations and formal help-seeking intentions through attitudes toward professional help-seeking. 


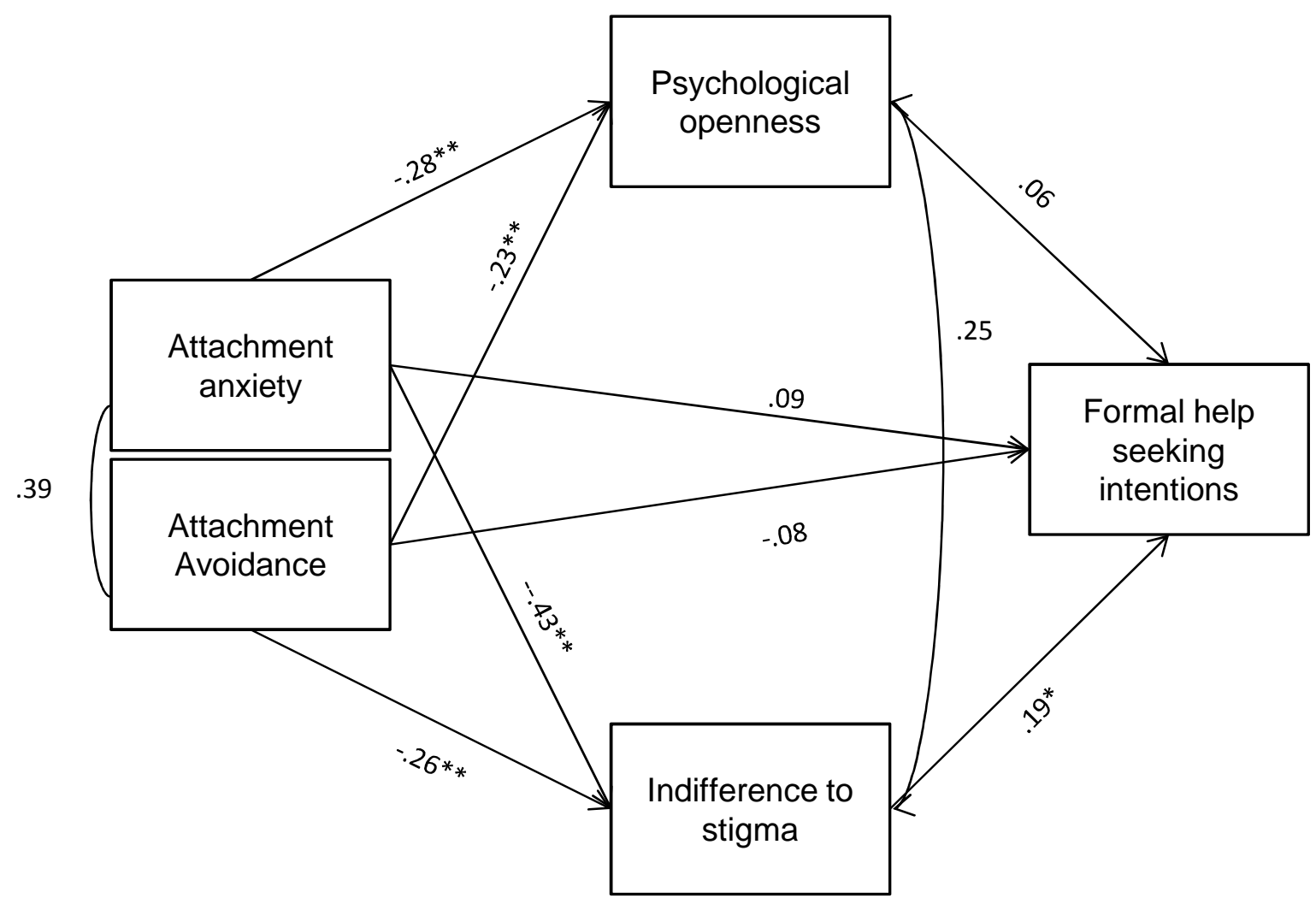

Figure 2. Direct and indirect effects of the attachment representations on intentions to use formal help-seeking.

Note: Values are standardized coefficients. ${ }^{*} p<0.05 ; * * p<0.001$ 


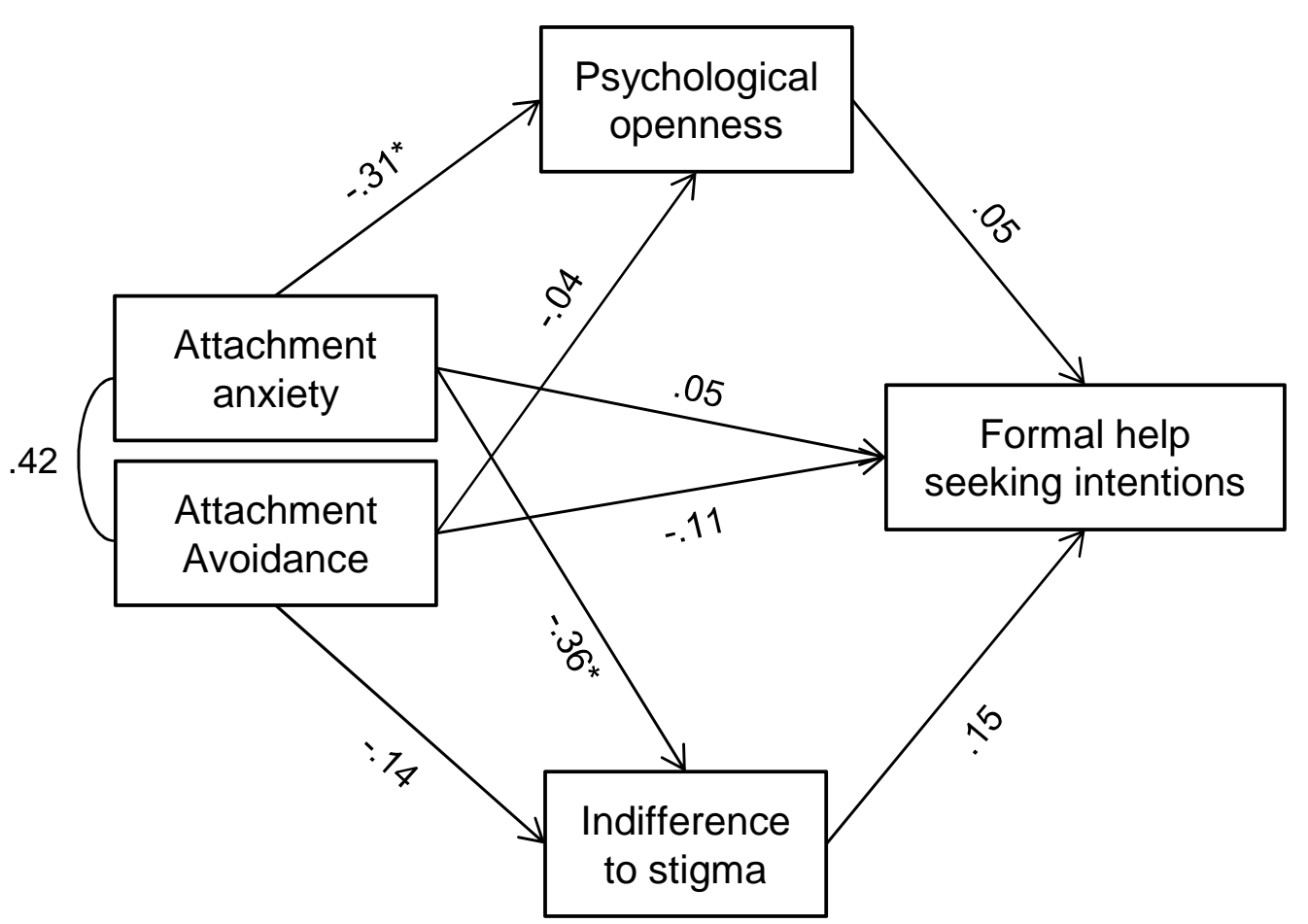

Group 1. Women with no psychopathological symptoms.

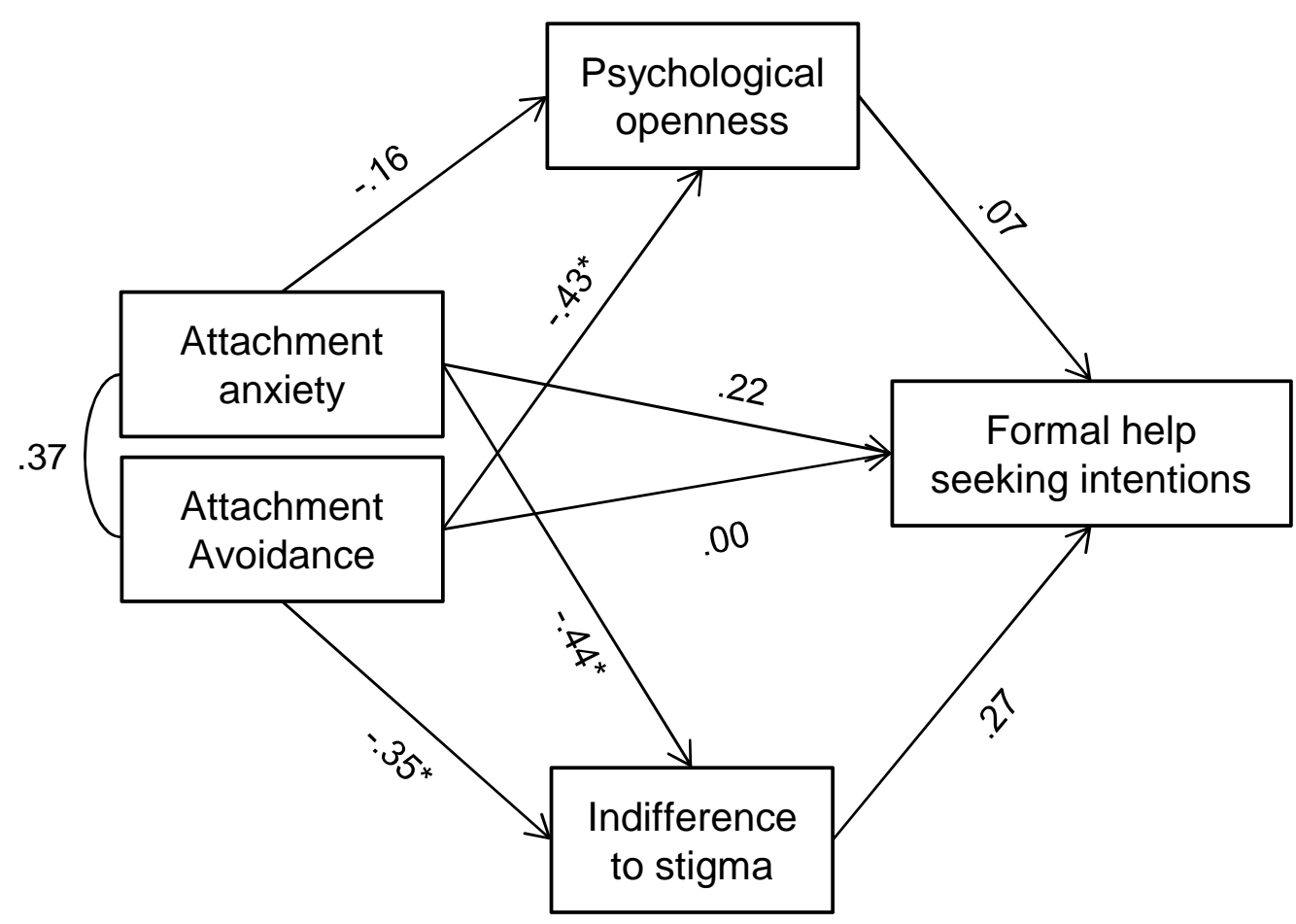

Group 2. Women with psychopathological symptoms.

Figure 3. Direct and indirect effects of the attachment representations on intentions to use formal help-seeking in the two groups of participants.

Note: Values are standardized coefficients. ${ }^{*} p<0.001$ 